\title{
Bartonella and intraocular inflammation: a series of cases and review of literature
}

This article was published in the following Dove Press journal:

Clinical Ophthalmology

17 June 2011

Number of times this article has been viewed

\author{
Chris Kalogeropoulos' \\ Ioannis Koumpoulis' \\ Andreas Mentis ${ }^{2}$ \\ Chrisavgi Pappa' \\ Paraskevas Zafeiropoulos' \\ Miltiadis Aspiotis' \\ 'Department of Ophthalmology, \\ Medical School, University of loannina, \\ Greece; ${ }^{2}$ Laboratory of Medical \\ Microbiology, Hellenic Pasteur \\ Institute, Athens, Greece
}

Correspondence: Chris D

Kalogeropoulos

PO Box 1080, 45 I I 0 loannina, Greece

Tel +302651070216

Fax +30 2651039473

Email chkalog@cc.uoi.gr
Purpose: To present various forms of uveitis and/or retinal vasculitis attributed to Bartonella infection and review the impact of this microorganism in patients with uveitis.

Methods: Retrospective case series study. Review of clinical records of patients diagnosed with Bartonella henselae and Bartonella quintana intraocular inflammation from 2001 to 2010 in the Ocular Inflammation Department of the University Eye Clinic, Ioannina, Greece. Presentation of epidemiological and clinical data concerning Bartonella infection was provided by the international literature.

Results: Eight patients with the diagnosis of Bartonella henselae and two patients with B. quintana intraocular inflammation were identified. Since four patients experienced bilateral involvement, the affected eyes totaled 14. The mean age was 36.6 years (range 12-62). Uveitic clinical entities that we found included intermediate uveitis in seven eyes (50\%), vitritis in two eyes $(14.2 \%)$, neuroretinitis in one eye $(7.1 \%)$, focal retinochoroiditis in one eye $(7.1 \%)$, branch retinal vein occlusion (BRVO) due to vasculitis in one eye $(7.1 \%)$, disc edema with peripapillary serous retinal detachment in one eye (7.1\%), and iridocyclitis in one eye (7.1\%). Most of the patients $(70 \%)$ did not experience systemic symptoms preceding the intraocular inflammation. Antimicrobial treatment was efficient in all cases with the exception of the case with neuroretinitis complicated by anterior ischemic optic neuropathy and tubulointerstitial nephritis.

Conclusion: Intraocular involvement caused not only by $B$. henselae but also by $B$. quintana is being diagnosed with increasing frequency. A high index of suspicion is needed because the spectrum of Bartonella intraocular inflammation is very large. In our study the most common clinical entity was intermediate uveitis.

Keywords: Bartonella, neuroretinitis, intermediate uveitis, retinal vascular occlusion

\section{Introduction}

The genus Bartonella includes more than 20 species, of which the members are small Gram-negative, fastidious, hemotropic, intracellular bacteria belonging to the $\alpha-2$ subdivision of proteobacteria. These bacteria can cause a long-lasting intraerythrocytic bacteremia in their mammalian reservoir hosts and are mainly transmitted by bloodsucking arthropod vectors. ${ }^{1}$ Several Bartonella species have been identified to cause human diseases. In this article we will focus on Bartonella henselae, Bartonella quintana and their ocular manifestations, mainly the intraocular ones (uveitis and/ or retinal vasculitis), with regard to our cases and data provided by the international literature. $B$. henselae has been most commonly implicated in intraocular inflammation, especially recently, and there are reports concerning various forms of intraocular inflammation (Table 1). 
Table I Bartonella species found to cause systemic and ocular manifestations

\begin{tabular}{|c|c|c|c|c|c|}
\hline Classification & & & & Human diseases & \\
\hline $\begin{array}{l}\text { Bartonella } \\
\text { species }\end{array}$ & $\begin{array}{l}\text { Reservoir } \\
\text { host }\end{array}$ & $\begin{array}{l}\text { Accidental } \\
\text { host }\end{array}$ & Vector & $\begin{array}{l}\text { Systemic } \\
\text { manifestations }\end{array}$ & Ocular manifestations \\
\hline B. henselae & Cats & Human, dog & $\begin{array}{l}\text { Cat flea, ticks?, } \\
\text { biting flies? }\end{array}$ & $\begin{array}{l}\text { CSD, FUO, hepatosplenic } \\
\text { abscesses, neurologic } \\
\text { manifestations, endocarditis, } \\
\text { myocarditis, glomerulonephritis, } \\
\text { pseudomalignancy, } \\
\text { osteomyelitis, BA, BP }\end{array}$ & $\begin{array}{l}\text { POGS, Neuroretinitis, retinitis, } \\
\text { choroiditis, intermediate uveitis, vascular } \\
\text { occlusions, vasculitis, iridocyclitis, } \\
\text { angiomatous lesions }\end{array}$ \\
\hline B. quintana & Human & $\begin{array}{l}\text { Cat, dog, } \\
\text { monkey }\end{array}$ & $\begin{array}{l}\text { Human body louse, } \\
\text { cat flea, ticks? }\end{array}$ & $\begin{array}{l}\text { Trench fever, endocarditis, BA, } \\
\text { lymphadenopathy }\end{array}$ & $\begin{array}{l}\text { Neuroretinitis, POGS, retinitis, vasculitis, } \\
\text { anterior, intermediate and posterior } \\
\text { uveitis }\end{array}$ \\
\hline B. grahamii & Rodent & Human & Rodent flea & & $\begin{array}{l}\text { Neuroretinitis, retinitis, vasculitis, papillitis, } \\
\text { anterior and posterior uveitis, retinal } \\
\text { vascular occlusion }\end{array}$ \\
\hline B. elizabethae & Rodent & Human, dog & Rodent flea & Endocarditis & Neuroretinitis \\
\hline
\end{tabular}

Abbreviations: CSD, cat scratch disease; FUO, fever of unknown origin; BA, bacillary angiomatosis; BP, bacillary peliosis; POGS, Parinaud's oculoglandular syndrome.

\section{Bartonella henselae}

The major host reservoir for $B$. henselae is cats. ${ }^{2}$ Many seroepidemiological studies have been published showing the worldwide distribution of $B$. henselae infection in cats. The antibody prevalence in cats varies from between $5 \%-10 \%$ up to $70 \%-80 \%$ depending on the geographical area tested and the domestic or stray cat status. ${ }^{3-9} B$. henselae causes intraerythrocytic bacteremia in cats for several weeks, but usually cats are asymptomatic. Transmission between cats depends on the arthropod vector Ctenocephalides felis, or the cat flea. ${ }^{10} \mathrm{~B}$. henselae can multiply within the digestive system of the cat flea and survives several days in the flea feces. The main source of infection for cats and also humans seems to be the inoculation of flea feces by contaminated cat claws with a cat scratch. ${ }^{1}$ Transmission to humans can also happen with cat biting or cat saliva through an open wound. The cat flea bite is probably another way of transmission to humans as well. Other possible vectors for $B$. henselae infection are ticks and biting flies. ${ }^{1}$ Dogs can be infected with $B$. henselae as well, but the role of dogs as reservoir hosts is less clear than cats. ${ }^{11}$

$B$. henselae causes a variety of manifestations in humans and the response depends on their immune status. In immunocompetent individuals the response is granulomatous and suppurative. In immunocompromised patients the response is mainly vasoproliferative. ${ }^{12}$

In immunocompetent individuals there is a wide spectrum of clinical manifestations:

1. Typical cat scratch disease is the most common manifestation. After a cat scratch at the site of the inoculation a papule or pustule is formed and there is a regional lymphadenopathy with or without fever. The affected nodes may become suppurative. ${ }^{13}$

2. Fever of unknown origin (FUO). Prolonged fever $>2$ weeks without any symptoms or signs of an obvious clinical disease. ${ }^{14}$

3. Ocular manifestations: Parinaud oculoglandular syndrome consists of follicular conjunctivitis and regional lymphadenopathy. Posterior segment manifestations include neuroretinitis, focal retinitis, choroiditis or retinochoroiditis, multifocal retinitis, choroiditis or retinochoroiditis, intermediate uveitis, branch retinal artery and vein occlusions, vasculitis and angiomatous vasoproliferative lesions that are rare and mostly seen in immunocompromised patients. ${ }^{15,16}$

4. Other clinical manifestations

Hepatosplenic manifestations: Granulomatous and suppurative disease of the liver and spleen with systemic symptoms as prolonged fever and with or without abdominal pain, hepatomegaly or splenomegaly. ${ }^{17}$

Cardiovascular manifestations: Endocarditis is the most common cardiac complication. Bartonella species are responsible for about $3 \%$ of cases of endocarditis. ${ }^{18,19}$ Myocarditis is a rare complication.

Neurologic manifestations: They are rare and include encephalopathy, seizures, status epilepticus, meningitis, meningoencephalitis, peripheral facial nerve paralysis, coma, transverse myelitis and acute hemiplegia. ${ }^{20-22}$

Hematologic manifestations: They are rare and include hemolytic anemia and thrombocytopenic purpura.

Renal manifestations: Glomerulonephritis is a rare complication. ${ }^{23}$ 
Orthopedic manifestations: Osteomyelitis and arthritis are rare complications. ${ }^{24,25}$

Pseudomalignancy: Simulating lymphoma, mimicking breast tumor, simulating a malignant process of the chest wall, simulating rhabdomyosarcoma, mimicking parotid malignancy. ${ }^{26-30}$

In immunocompromised patients the response is mainly vasoproliferative:

Bacillary angiomatosis: Refers to skin proliferative vascular lesions that may resemble Kaposi's sarcoma. Red or brown papules, angiomatous nodules, pedunculated lesions, or deep subcutaneous masses. ${ }^{31,32}$

Bacillary peliosis: Refers to proliferative vascular lesions in liver and spleen. ${ }^{33}$

\section{Bartonella quintana}

The major reservoir hosts for $B$. quintana are humans. The disease is transmitted among humans by the human body louse, Pediculus humanus corporis. The human body louse lives on the body and in the clothes or bedding of its human host. ${ }^{34}$ Seroepidemiological studies in homeless people living in poor conditions show an antibody prevalence that varies from $2 \%$ up to $57 \%$. ${ }^{35-38}$ B. quintana can multiply within the digestive system of the louse and survives in louse feces. Transmission to humans occurs via inoculation of infectious louse feces through altered skin. ${ }^{1}$ Lice cause local skin irritation because they inject biological proteins with their bites resulting in itching, scratching and inoculation of B. quintana. Transmission of B. quintana to a human has also been demonstrated to happen with a cat bite. ${ }^{39}$ B. quintana has been found present in dogs, cats, ${ }^{40}$ cat fleas and also monkeys. ${ }^{41}$ Ticks could also be a possible vector. ${ }^{11}$

\section{Clinical manifestations}

1. Trench fever. During World War I more than 1 million people were infected. After World War II the incidence of the disease was very low but recently the incidence increased in people living in poor conditions and occasionally infested by body lice such as the homeless, drug addicts and alcoholics. Trench fever is characterized by recurrent attacks of 5-day cycling fever, headaches and dizziness. ${ }^{34,42}$

2. Chronic bacteremia.

3. Endocarditis. ${ }^{18}$

4. Bacillary angiomatosis, especially in immunocompromised individuals. ${ }^{34,42}$

5. Lymphadenopathy.
6. Ocular manifestations: neuroretinitis, anterior, intermediate and posterior uveitis. ${ }^{43}$

\section{Ocular manifestations of Bartonella infection}

The most common ocular manifestation of $B$. henselae infection is Parinaud's oculoglandular syndrome (POGS). The syndrome was named after Henri Parinaud who described it for the first time in $1889 .{ }^{44}$ Nearly $5 \%$ of symptomatic patients with cat scratch disease have POGS. ${ }^{13}$ Patients present with fever, granulomatous conjunctivitis and regional lymphadenopathy affecting the preauricular, submandibular or cervical lymph nodes. Typical symptoms include unilateral eye redness, foreign body sensation and epiphora. ${ }^{15}$ Transmission is considered to happen through inoculation of contaminated flea feces from the hands to the eye, because direct cat scratches to the conjunctiva are unusual. ${ }^{16} B$. quintana has also been found in a case report to be the causative organism in a patient with POGS. ${ }^{45}$

Neuroretinitis affects $1 \%$ to $2 \%$ of patients with $B$. henselae infection. ${ }^{13,46}$ There is optic nerve head swelling with complete or partial macular star formation. Among patients with neuroretinitis the most common cause is $B$. henselae and approximately two-thirds have positive serologic testing. ${ }^{47}$ Patients present with unilateral, painless, sudden visual loss and systemic symptoms can also be present. ${ }^{48}$ Bilateral neuroretinitis is rare and the simultaneous presence of neuroretinitis and POGS is also uncommon. ${ }^{49,50}$ Some patients with neuroretinitis also present with multifocal retinochoroiditis. ${ }^{48}$ Optic disc edema associated with peripapillary serous retinal detachment can be an early sign of systemic $B$. henselae infection. ${ }^{51}$ Usually after 2 to 4 weeks a macular star formation follows, but in some patients this may not happen. The macular exudates may take months to resolve. After the resolution of neuroretinitis, a mild optic neuropathy may persist. Some patients may have disc pallor, decreased contrast sensitivity, abnormal visually evoked potentials, dyschromatopsia and persistent afferent pupillary defects. ${ }^{52}$ Other causes of neuroretinitis that should be included in the differential diagnosis are syphilis, tuberculosis, Lyme disease, toxoplasmosis, toxocariasis, leptospirosis, sarcoidosis, malignant hypertension, diabetes and increased intracranial pressure. ${ }^{15,16}$ B. quintana, B. grahamii and $B$. elizabethae have also been found to be causes of neuroretinitis. ${ }^{53-55}$

Other posterior segment manifestations of patients with $B$. henselae infection include focal or multifocal retinitis, 
choroiditis or retinochoroiditis with or without the presence of neuroretinitis or disc edema. Branch retinal artery and vein occlusions and serous retinal detachment, macular hole, panuveitis with diffuse choroidal thickening simulating Vogt-Koyanagi-Harada syndrome, vitritis, vasculitis and papillitis have been noted by several authors. ${ }^{48,56-62}$ B. quintana and B. grahamii have been found to be causes of retinitis, vasculitis and papillitis. ${ }^{43} B$. grahamii has also been found to cause retinal vascular occlusion. ${ }^{63}$

In immunocompromised patients with $B$. henselae infection, retinal bacillary angiomatosis and subretinal vascular mass have been observed. ${ }^{64}$ Angiomatous lesions have also been observed in immunocompetent patients. ${ }^{56}$ Anterior and intermediate uveitis can be seen in $B$. henselae and B. quintana infection. ${ }^{43,65}$ B. grahamii also can cause anterior uveitis. $^{43}$

\section{Patients and methods}

In a series of consecutive patients with intraocular inflammation (ie, uveitis, retinal vasculitis) examined and treated during the recent 10 years in the Ocular Inflammation Department of the University Eye Clinic of Ioannina (Greece), the implication of both $B$. henselae and $B$. quintana was also explored. In all patients, a meticulous diagnostic approach to inflammation was carried out, concerning infectious diseases (including brucellosis, tuberculosis, syphilis, toxoplasmosis, toxocariasis, leptospirosis, Lyme disease, bartonellosis and infection due to herpes simplex virus, herpes zoster virus, cytomegalovirus, Epstein-Barr virus and human immunodeficiency virus I+II), sarcoidosis and other autoimmune diseases, and specific idiopathic uveitic syndromes as well.

The diagnosis of a Bartonella infection was based on:

1. History of traumatic cat exposure (scratching and/or biting) or even licking through an open wound.

2. Serologic testing for $B$. henselae and $B$. quintana using indirect fluorescence assay (IFA). The laboratory examination of the sera was carried out at the Pasteur Institute of Athens. Titers $<1: 32$ were considered negative, titers of $\geq 1: 64$ were considered positive (high diagnostic value), titers $=1: 32$ were considered uncertain (moderate diagnostic value). ${ }^{66}$ The sensitivity and specificity of the test depend on the serological cutoff value chosen. For a cutoff value $=1: 32$ (sensitivity $=0.80$ specificity $=0.85$ ). For a cutoff value of $\geq 1: 64$ ( sensitivity $=0.70$; specificity $=0.95)$. The best compromise between specificity and sensitivity is obtained with a cutoff value between 1:32 and 1:64. ${ }^{66}$ In our cases with positive history of cat attack and absence of another diagnosis, the cutoff value 1:32 was considered as positive in order to avoid an underdiagnosis of Bartonella infection.

3. Presence of an intraocular inflammation not attributed to other causes.

4. Previous illness (preceding the intraocular inflammation).

5. Presence of human body lice.

Patients with a diagnosis of Bartonella intraocular inflammation were treated with the appropriate antibiotics (the main antibiotics used were doxycycline, rifampicin and azithromycin) $)^{16}$ and were followed-up for the evaluation of the final outcome of the ocular disease and for any eventual systemic complication due to Bartonellosis.

Our results were compared to those of other authors with regard to the intraocular findings (anterior uveitis, intermediate uveitis, vitritis, neuroretinitis, choroiditis, retinal vasculitis and vascular occlusion), diagnostic approach, appropriate treatment and outcome. A thorough analysis of the data provided by the international literature regarding Bartonella ocular infections, with a particular focus on intraocular involvement, was carried out in order to obtain a profile of the manifestations of intraocular infection due to Bartonella species, and avoid underdiagnosis.

\section{Results}

Intraocular inflammation was attributed to Bartonella (either henselae or quintana) in 10 patients. This number constitutes $0.33 \%$ of the cases with uveitis examined in our department during the same period (last decade). Table 2 presents the profile of patients with intraocular inflammation considered to be of Bartonella origin. Ages ranged from 12 to 62 years (mean age 36.6). In eight patients the causative organism was $B$. henselae. In seven of them there was a history of traumatic cat exposure (scratching and/or biting) and in one of them there was a history of cat licking through an open wound. In two patients the causative organism was $B$. quintana. In these two patients, one had pubic lice and the other was a worker in the fur industry, suggesting a possible tick or flea bite. Neither patient had a history of traumatic cat exposure.

In our series of ten patients, six patients were male and four female. Four patients had bilateral involvement and there were 14 affected eyes. In terms of eye involvement the clinical findings were: intermediate uveitis in seven eyes $(50 \%)$; vitritis in two eyes $(14.2 \%)$; neuroretinitis in one eye $(7.1 \%)$; focal retinochoroiditis in one eye $(7.1 \%)$; branch retinal vein occlusion (BRVO) due to vasculitis in one eye $(7.1 \%)$; disc edema with peripapillary serous retinal detachment in one eye $(7.1 \%)$; and recurrent iridocyclitis 
Table 2 Profile of patients with intraocular inflammation considered of Bartonella origin

\begin{tabular}{|c|c|c|c|c|c|}
\hline $\begin{array}{l}\text { Patients } \\
\text { (gender, age) }\end{array}$ & $\begin{array}{l}\text { Mode of } \\
\text { transmission }\end{array}$ & $\begin{array}{l}\text { Preceding clinical } \\
\text { manifestations }\end{array}$ & $\begin{array}{l}\text { Intraocular } \\
\text { manifestations }\end{array}$ & Microorganism & $\begin{array}{l}\text { IgG titers } \\
\text { (IFA) }\end{array}$ \\
\hline I. M 60 & Scratching & & Neuroretinitis & B. henselae & $\mathrm{I}: 32$ \\
\hline 2. F I2 & Scratching & $\begin{array}{l}\text { ( } \mathrm{f} I \mathrm{~m} \text { before uveitis } \\
\text { signs and } 2 \mathrm{w} \text { after scratching) }\end{array}$ & Focal retinochoroiditis & B. henselae & $\mathrm{I}: 32$ \\
\hline 3. M 3I & Scratching and biting & & Vitritis $^{\mathrm{b}}$ & B. henselae & $\mathrm{I}: 64$ \\
\hline 4. M 36 & Scratching & & BRVO (+ periphlebitis) & B. henselae & $1: 32$ \\
\hline 5. M 30 & Scratching & $\begin{array}{l}\text { (Skin pustule at scratching } \\
\text { site } 6 \mathrm{w} \text { before uveitis onset) }\end{array}$ & Intermediate uveitis & B. henselae & $\mathrm{I}: 64$ \\
\hline 6. F 28 & Scratching & & Intermediate uveitis ${ }^{c}$ & B. henselae & $\mathrm{I}: 32$ \\
\hline 7. M 4I & Scratching & $\begin{array}{l}\text { (POGS, malaise } 3 \mathrm{w} \text { before } \\
\text { uveitis signs) }\end{array}$ & Intermediate uveitis ${ }^{c}$ & B. henselae & $1: 32$ \\
\hline 8. F 27 & Pubic lice & & Intermediate uveitis ${ }^{c}$ & B. quintana & $\mathrm{I}: 128$ \\
\hline 9. F 39 & $\begin{array}{l}\text { Worker in furs } \\
\text { elaboration industry }\end{array}$ & & Recurrent iridocyclitis & B. quintana & $\mathrm{I}: 64$ \\
\hline 10. M 62 & Licking & & $\begin{array}{l}\text { Optic disc edema with } \\
\text { peripapillary SRD }\end{array}$ & B. henselae & $\mathrm{I}: 128$ \\
\hline
\end{tabular}

Notes: aPossible tick or flea bite; 'Bilateral vitritis; 'Bilateral involvement along with peripheral vasculitis.

Abbreviations: $f$, fever; $m$, month; $w$, weeks; POGS, Parinaud's oculoglandular syndrome; BRVO, branch retinal vein occlusion; SRD, serous retinal detachment.

in one eye $(7.1 \%)$. The most common uveitic entity in our series of cases was intermediate uveitis. Since all patients with intermediate uveitis were young adults (27-41 years), neurological examination and MRI of the brain were carried out to rule out a multiple sclerosis background. The results were negative for multiple sclerosis.

The great majority of the cases (70\%) did not experience a systemic or another ocular illness preceding the intraocular inflammatory manifestations (Table 2). Antimicrobial treatment was efficient in all cases with the exception of the case with neuroretinitis complicated by anterior ischemic optic neuropathy and tubulointerstitial nephritis (case 1). The main antibiotics administered in our cases were rifampicin, doxycycline and azithromycin. Ciprofloxacin and ceftriaxone were also used in cases with treatment failure, allergy and early side-effects. Table 3 presents the visual acuities before and after treatment, the antibiotics used to eradicate the microorganism, and the complications seen during follow-up.

\section{Case reports Case I}

Sixty-year-old male with a history of cat scratching and without any systemic manifestations. In his left eye, neuroretinitis was observed 1 month after cat scratching (Figure 1A). The IgG titer for $B$. henselae was 1:32. The visual acuity in the affected left eye was 0.05 before treatment. The right eye was not affected. He was treated with ciprofloxacin $750 \mathrm{mg}$ daily and doxycycline $100 \mathrm{mg} 12$ hourly for 4 weeks, followed by ceftriaxone $1 \mathrm{~g}$ 12-hourly for 1 week. The visual acuity after treatment was 0.025 . This patient developed anterior ischemic optic neuropathy (AION) 3 weeks after the onset of disease (neuroretinitis) with characteristic visual field defect and had a poor outcome in spite of treatment (Figure 1B); in addition, tubulointerstitial nephritis occurred 3 months after the diagnosis of neuroretinitis suggesting possible tubulointerstitial nephritisuveitis (TINU) syndrome. ${ }^{67}$ This patient had abnormal renal function with elevated serum creatinine. The urine analysis was abnormal showing low grade proteinuria, hematuria and increased beta- 2 microglobulin. Also mild anemia (hemoglobin $12 \mathrm{~g} / \mathrm{dL}$ ) and an abnormal elevated erythrocyte sedimentation rate (ESR $96 \mathrm{~mm} / \mathrm{hour}$ ) were noted. A renal biopsy was not performed and the patient was treated successfully with systemic corticosteroids for the renal disease. The final visual acuity of his left eye was counting fingers at $30 \mathrm{~cm}$.

\section{Case 2}

Twelve-year-old girl with a history of cat scratch and fever 2 weeks later. Six weeks after the cat scratch, a focal retinochoroiditis was observed in her right eye. The IgG titer for $B$. henselae was $1: 32$. The visual acuity in the affected right eye was 0.5 before treatment. The left eye was not affected. She was treated with rifampicin $600 \mathrm{mg}$ daily and doxycycline $100 \mathrm{mg} 12$ hourly for 4 weeks with complete resolution of the uveitis. The visual acuity after treatment in the affected right eye was 1.0. During the follow-up, a chorioretinal extrafoveal scar was observed in the location of the focal retinochoroiditis, which did not affect visual acuity.

\section{Case 3}

Thirty-one-year-old male with a history of cat scratching and biting and without any systemic symptoms. Bilateral vitritis 
Table 3 Treatment and outcome in ten cases with intraocular inflammation due to B. henselae and B. Quintana

\begin{tabular}{|c|c|c|c|c|c|c|}
\hline \multicolumn{2}{|c|}{$\begin{array}{l}\text { VA } \\
\text { (before treatment) }\end{array}$} & \multicolumn{2}{|c|}{$\begin{array}{l}\text { VA } \\
\text { (after treatment) }\end{array}$} & \multirow[t]{2}{*}{ Treatment } & \multirow[t]{2}{*}{$\begin{array}{l}\text { Follow-up } \\
\text { (years) }\end{array}$} & \multirow[t]{2}{*}{ Complications } \\
\hline RE & LE & RE & LE & & & \\
\hline 1.0 & 0.05 & 1.0 & 0.025 & $\begin{array}{l}\text { Ciprofloxacin } 750 \text { mg (daily) } \\
\text { Doxycycline } 100 \text { mg ( } 12 \text {-hourly) } \\
4 \text { weeks } \\
\text { Followed by (IV) } \\
\text { Ceftriaxone I g (I2-hourly) } \\
\text { I week }\end{array}$ & 6 & $\begin{array}{l}\text { AION (arteritic) RE, } \\
\text { TINU } \\
\text { Final VA RE: } \\
\mathrm{CF} / 30 \mathrm{~cm}\end{array}$ \\
\hline 0.5 & 1.0 & 1.0 & 1.0 & $\begin{array}{l}\text { Rifampicin } 600 \mathrm{mg} \text { (daily) } \\
\text { Doxycycline } 100 \mathrm{mg} \\
\text { (I2-hourly) } 4 \text { weeks }\end{array}$ & 7 & $\begin{array}{l}\text { Chorioretinal scar } \\
\text { RE (extrafoveal) }\end{array}$ \\
\hline 0.9 & 0.8 & 1.0 & 1.0 & $\begin{array}{l}\text { Rifampicin } 600 \text { mg (daily) } \\
\text { Azithromycin } 500 \text { mg (daily) } \\
4 \text { weeks }\end{array}$ & 5 & $\begin{array}{l}\text { Myocarditis (I year } \\
\text { after the onset of } \\
\text { the ocular disease) }\end{array}$ \\
\hline 1.0 & 0.8 & 1.0 & 1.0 & $\begin{array}{l}\text { Rifampicin } 600 \mathrm{mg} \text { (daily) } \\
\text { Azithromycin } 500 \mathrm{mg} \\
\text { (daily) } 4 \text { weeks }\end{array}$ & 2.5 & \\
\hline 1.0 & 0.5 & 1.0 & 1.0 & $\begin{array}{l}\text { Ciprofloxacin } 500 \text { mg (12-hourly) } \\
4 \text { weeks }\end{array}$ & 7 & $\begin{array}{l}\text { ERM of the macula } \\
\text { (VA LE: } 1.0 \rightarrow 0.9 \text { ) }\end{array}$ \\
\hline 0.6 & 0.8 & 1.0 & 1.0 & $\begin{array}{l}\text { Rifampicin } 600 \text { mg (daily) } \\
\text { Doxycycline } 100 \text { mg (I2-hourly) } \\
4 \text { weeks }\end{array}$ & I & \\
\hline 0.7 & 0.8 & 1.0 & 1.0 & $\begin{array}{l}\text { Rifampicin } 600 \text { mg (daily) } \\
\text { Doxycycline } 100 \text { mg (12-hourly) } \\
4 \text { weeks }\end{array}$ & 2 & $\begin{array}{l}\text { ERM of the macula } \\
\text { (VA RE: I.0 } \rightarrow 0.8 \text { ) }\end{array}$ \\
\hline 0.9 & 0.9 & 1.0 & 1.0 & $\begin{array}{l}\text { Rifampicin } 600 \text { mg (daily) } \\
\text { Doxycycline } 100 \text { mg (12-hourly) } \\
4 \text { weeks }\end{array}$ & 2 & \\
\hline 1.0 & 0.8 & 1.0 & 1.0 & $\begin{array}{l}\text { Doxycycline } 100 \text { mg (12-hourly) } \\
\text { Azithromycin } 500 \text { mg (daily) } \\
4 \text { weeks }\end{array}$ & 3 & $\begin{array}{l}\text { Cataract formation } \\
(\text { VA LE: } 1.0 \rightarrow 0.9)\end{array}$ \\
\hline 0.7 cataract & 0.4 & 0.7 cataract & 0.9 & $\begin{array}{l}\text { Rifampicin } 600 \text { mg (daily) } \\
\text { Doxycycline } 100 \text { mg (12-hourly) } \\
4 \text { weeks }\end{array}$ & I & \\
\hline
\end{tabular}

Note: The visual acuities in bold italics concern the affected eyes.

Abbreviations: R, rifampicin; D, doxycycline; A, azithromycin; IV, intravenous; AION, anterior ischemic optic neuropathy; TINU, tubular interstitial nephritis and uveitis; ERM, epiretinal membrane; VA, visual acuity, RE, right eye; LE, left eye.
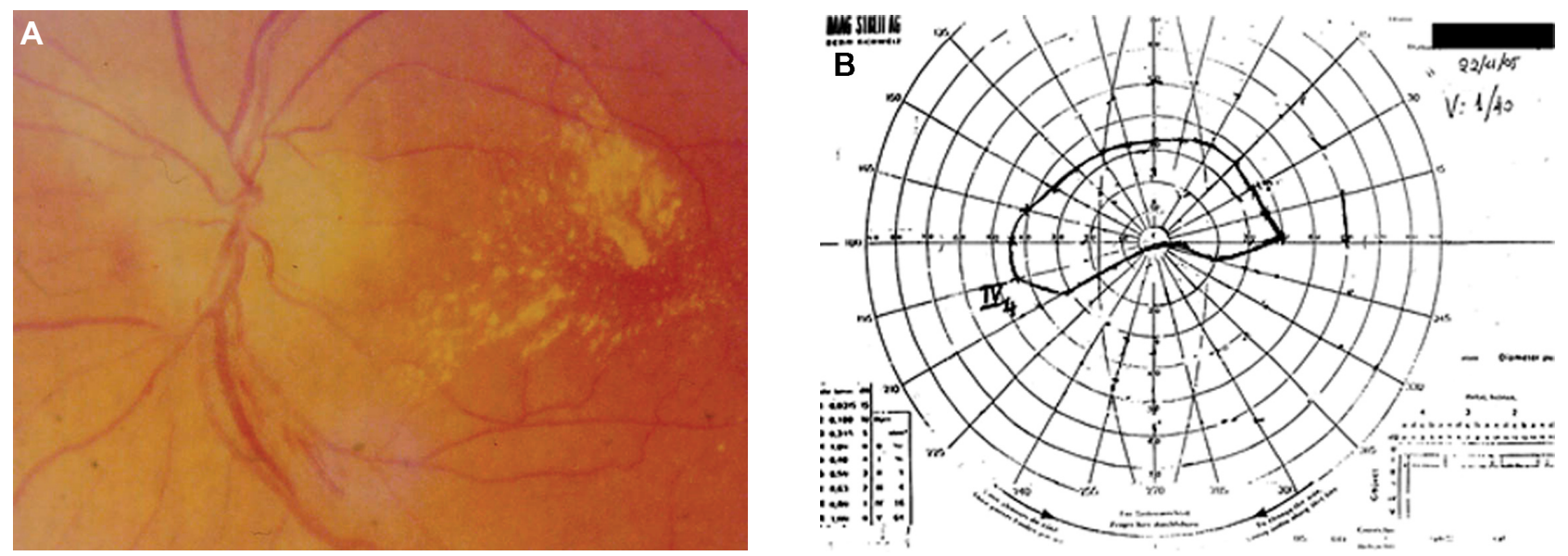

Figure I Patient I (Tables 2 and 3) with neuroretinitis: optic disc edema and macular star (A) and AION (B) with characteristic visual fields defect and positive serology for Bartonella henselae and history of cat scratch.

Abbreviation: AION, anterior ischemic optic neuropathy. 
was observed 6 weeks after cat scratching. The IgG titer for $B$. henselae was 1:64. The visual acuities before treatment in the affected eyes were 0.9 in the right eye and 0.8 in the left eye. He was treated with rifampicin $600 \mathrm{mg}$ daily and azithromycin $500 \mathrm{mg}$ daily for 4 weeks with complete resolution of the uveitis. The visual acuities after treatment were 1.0 in both eyes. One year after the onset of uveitis, the patient developed myocarditis, ${ }^{68}$ not associated with another preexisting heart disease with regard to cardiological investigation. The medical history of the patient was also negative for other infectious diseases causing myocarditis.

\section{Case 4}

Thirty-six-year-old male with BRVO in his left eye and recurrence of macular edema after the treatment with laser photocoagulation and intravitreal bevacizumab (Figure 2A, B, C, D). A more meticulous medical history revealed a recent episode of cat scratching 4 weeks before the onset of BRVO without any systemic symptoms. In addition, pedantic analysis of fluorescein angiography features took into account along with the BRVO the presence of retinal phlebitis (Figure 2C and D). Therefore, a diagnostic approach for retinal vasculitis and laboratory examination of the serum for $B$. henselae and quintana was carried out. The IgG titer for $B$. henselae was 1:32. Visual acuity before treatment in the affected left eye was 0.8 . He was treated with rifampicin $600 \mathrm{mg}$ daily and azithromycin $500 \mathrm{mg}$ daily for 4 weeks, resulting in an improvement of visual acuity and regression of macular edema (Figure 2E, F, G, H). The visual acuity after treatment in the affected left eye was 1.0. No recurrence either of macular edema or of retinal vasculitis was observed during a long follow-up period (2 1/2 years).

\section{Case 5}

Thirty-year-old male with a history of cat scratching. At the site of inoculation a pustule was formed and after 6 weeks intermediate uveitis was observed in his left eye (Figure 3A). The IgG titer for $B$. henselae was 1:64. The visual acuity before treatment in the affected left eye was 0.5 . The right eye was not affected. He was treated with ciprofloxacin $500 \mathrm{mg}$ 12-hourly for 4 weeks with complete resolution of the intermediate uveitis (Figure 3B). The visual acuity after treatment in the affected left eye was 1.0. A late complication was noticed in the left eye during follow-up; an epiretinal membrane of the macula was observed and the final visual acuity was 0.9 .

\section{Case 6}

Twenty-eight-year-old female with a history of cat scratching and without any systemic symptoms. Bilateral intermediate uveitis along with peripheral vasculitis was observed 5 weeks after cat scratching. The IgG titer for B. henselae was 1:32. The visual acuities in the affected eyes before treatment were 0.6 in the right eye and 0.8 in the left eye. She was treated with rifampicin $600 \mathrm{mg}$ daily and doxycycline $100 \mathrm{mg}$ 12-hourly for 4 weeks with complete resolution of the bilateral uveitis. The visual acuities after treatment in the affected eyes were $1.0 \mathrm{in}$ both of them.

\section{Case 7}

Forty-one-year-old male with a history of cat scratching followed after 2 weeks by malaise along with POGS. Five weeks after cat scratching, bilateral intermediate uveitis along with peripheral vasculitis was observed. The IgG titer for $B$. henselae was 1:32. The visual acuities before treatment in the affected eyes were 0.7 in the right eye and 0.8 in the left eye. He was treated with rifampicin $600 \mathrm{mg}$ daily and doxycycline $100 \mathrm{mg}$ 12-hourly for 4 weeks with complete resolution of the bilateral intermediate uveitis. The visual acuities after treatment in the affected eyes were 1.0 in both of them. A late complication was noticed in the right eye during follow-up; an epiretinal membrane of the macula was observed and the final visual acuity was 0.8 .

\section{Case 8}

Twenty-seven-year-old female with a history of pubic lice and without any systemic symptoms. She did not have a history of traumatic cat exposure. Bilateral intermediate uveitis along with peripheral vasculitis was observed (Figure 4A, B, C, D). The IgG titer for B. quintana was $1: 128$. The visual acuities before treatment in the affected eyes were 0.9 in the right eye and 0.9 in the left eye. She was treated with rifampicin $600 \mathrm{mg}$ daily and doxycycline $100 \mathrm{mg}$ 12-hourly for 4 weeks with complete resolution of the bilateral intermediate uveitis. The visual acuities after treatment in the affected eyes were 1.0 in both of them.

\section{Case 9}

Thirty-nine-year-old female with a history of recurrent unilateral iridocyclitis. She had three recurrences of inflammation in her left eye in a period of 1 year before the examination in our department. The iridocyclitis was a nongranulomatous one with posterior synechiae (Figure 5). She did not have any systemic symptoms. The IgG titer for B. quintana was 1:64. She was a worker in the furs elaboration industry, suggesting a possible tick or flea bite. She didn't have a history of traumatic cat exposure. The visual acuity before treatment in the affected left eye was 0.8 . The right eye was not affected. 

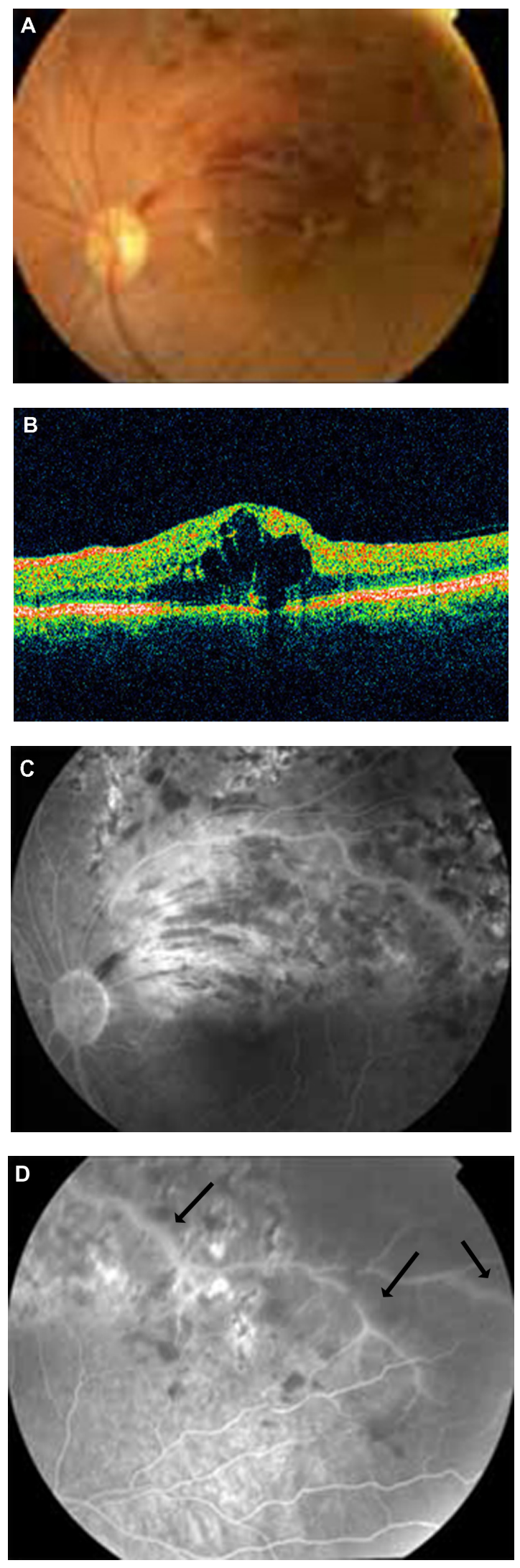
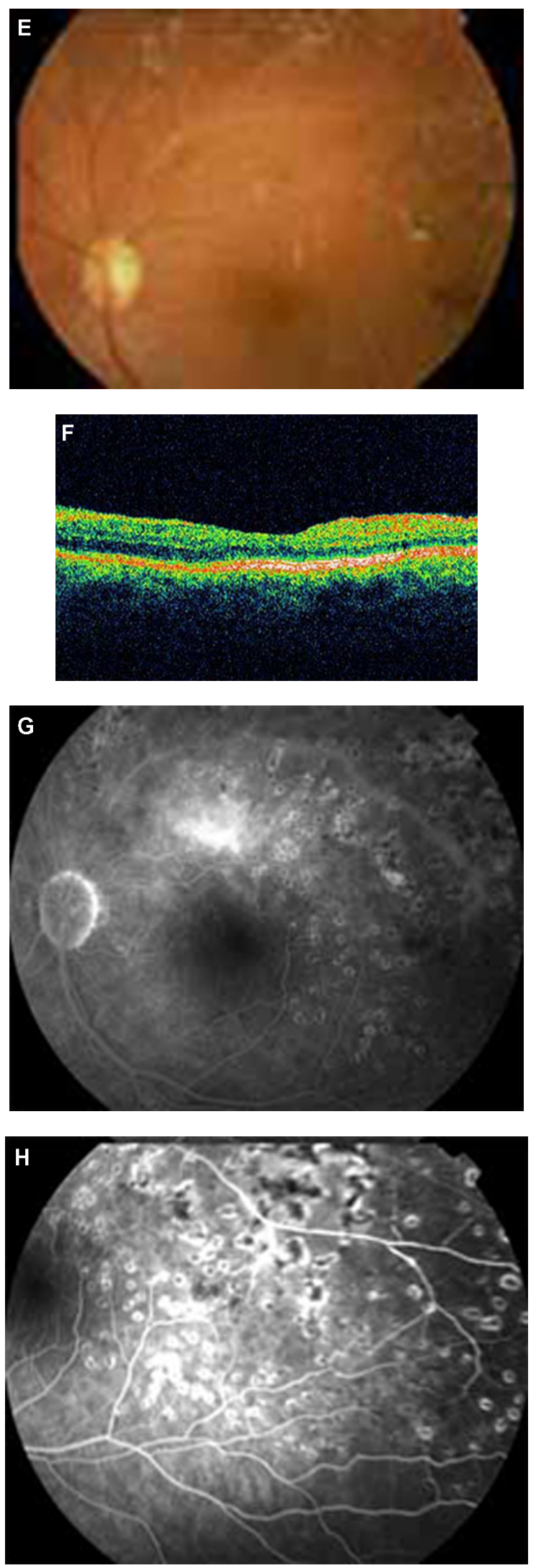

Figure 2 Patient 4 (Tables 2 and 3). A, B, C, D: BRVO along with cystoid macular edema (CME) in OCT and signs of vasculitis (FA arrows) treated previously with laser and intravitreal bevacizumab (positive serology for Bartonella henselae and history of cat scratch). E, F, G, H: After 4 weeks' treatment with azithromycin and rifampicin, there is a significant improvement of fundus findings along with FA findings and total regression of CME (OCT).

Abbreviations: BRVO, branch retinal vein occlusion; FA, fluorescein angiography; OCT, optical coherence tomography; CME, cystoid macular edema. 

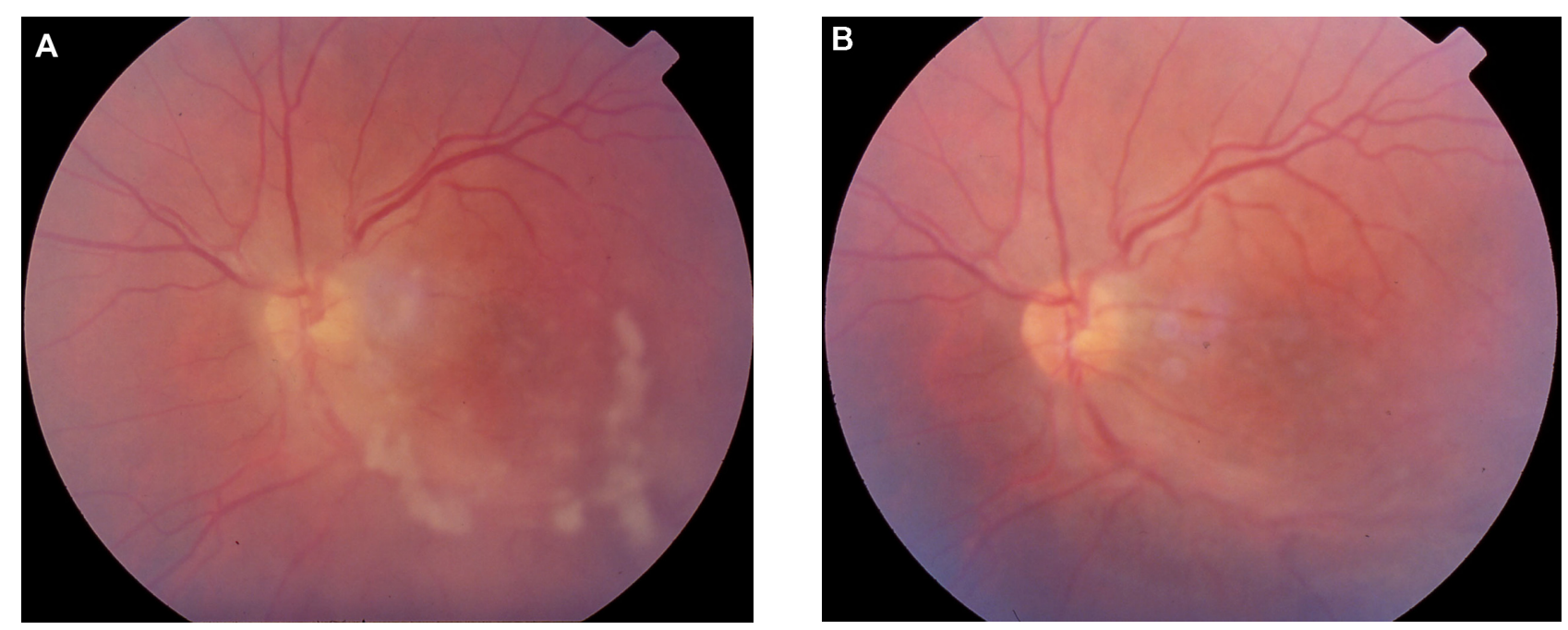

Figure 3 Patient 5 (Tables 2 and 3) with positive serology for Bartonella henselae and history of cat scratch, presenting with unilateral intermediate uveitis. A) before treatment and B) after 4 weeks treatment with ciprofloxacin: regression of uveitis (the absence of snowballs is notable).
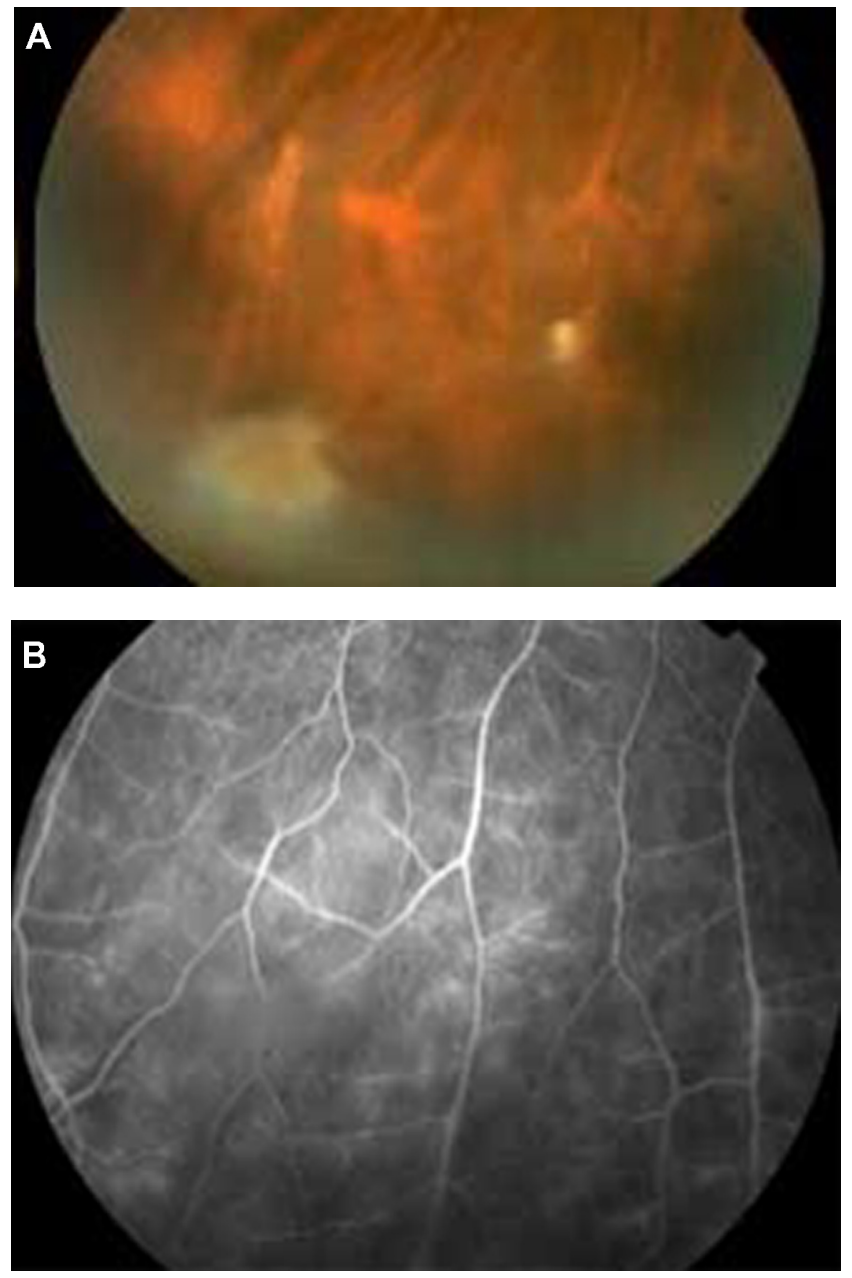

Figure 4 Patient with bilateral intermediate uveitis and peripheral vasculitis (increased lgG titers against B. quintana; patient 8 in Tables 2 and 3). (A) and (B) right eye with snowballs masking the vessels with mild vasculitis in fluorescein angiography (FA), (C) and (D) the vasculitis is more prominent in left eye; in FA segmental periphlebitis is present. 


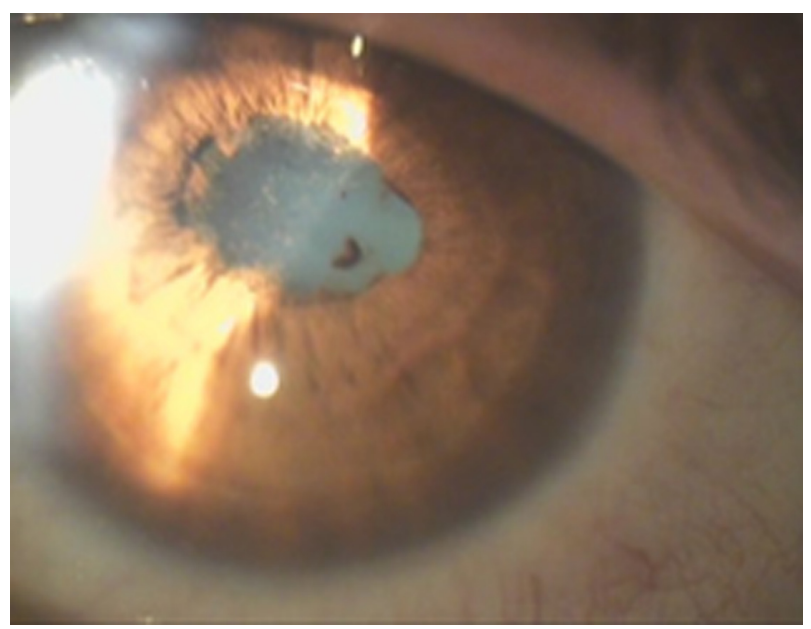

Figure 5 Recurrent nongranulomatous iridocyclitis with posterior synechiae in the left eye of a patient working in a furs elaboration industry, with positive serology for B. quintana (patient 9 in Tables 2 and 3).

She was treated with doxycycline $100 \mathrm{mg}$ 12-hourly and azithromycin $500 \mathrm{mg}$ daily for 4 weeks with complete resolution of the uveitis. The visual acuity after treatment in the affected left eye was 1.0. There were no recurrences during the 3-year follow-up period. Because of cataract formation in the left eye during follow-up, the final visual acuity in the left eye was 0.9 .

\section{Case 10}

Sixty-two-year-old male with a history of cat licking through an open wound and without any systemic symptoms. Optic disc edema associated with peripapillary serous retinal detachment was observed in his left eye 5 weeks after cat licking. The IgG titer for $B$. henselae was 1:128. The visual acuity before treatment in the affected left eye was 0.4 . The right eye was not affected. He was treated with rifampicin $600 \mathrm{mg}$ daily and doxycycline $100 \mathrm{mg}$ 12-hourly for 4 weeks with complete resolution of the uveitis. Visual acuity after treatment in the affected left eye was 0.9 .

\section{Discussion}

Our knowledge about Bartonella species has increased in the last few years and there are many reports about ocular manifestations of Bartonella infection. B. henselae has been found to cause POGS, neuroretinitis, retinochoroiditis, retinal vascular occlusions, vasculitis, vitritis, anterior uveitis, intermediate uveitis, posterior uveitis, papillitis and other ocular complications. ${ }^{15,16,43,46,48,56,59}$ B. quintana has been found to cause POGS, neuroretinitis, retinitis, vasculitis, papillitis, anterior, intermediate and posterior uveitis. ${ }^{43,45,53}$ B. grahamii has been found to cause retinitis, vasculitis, papillitis, retinal vascular occlusion, anterior and posterior uveitis. ${ }^{43,63}$ B. elizabethae has been found to cause neuroretinitis. ${ }^{55}$ It is important in patients with these ocular manifestations to know if there is a history of traumatic cat exposure, the presence of systemic symptoms such as fever, headache, lymphadenopathy or the presence of body lice. Since uveitis seems to be an emerging clinical form of Bartonella infection, patients with uveitis of unknown etiology should be tested for Bartonella species. ${ }^{43}$

The most common uveitic entity in our series of cases was intermediate uveitis. In the patients with intermediate uveitis snowballs and/or snowbanks were noted and three of them had bilateral involvement with peripheral vasculitis. There was also a patient with bilateral vitritis. According to the Standardization of Uveitis Nomenclature (SUN) working group ${ }^{69}$ vitritis is included in the clinical entity of intermediate uveitis. This means that the total number of affected eyes with intermediate uveitis was nine (64.2\%). To our knowledge this is the first report of a series of cases of ocular bartonellosis in which intermediate uveitis is the prominent clinical entity. In other published series of cases, neuroretinitis associated with macular $\operatorname{star}^{57}$ and isolated foci of retinitis or choroiditis ${ }^{70}$ were the most common intraocular findings in cat scratch disease (CSD). In a recent study from two Brazilian uveitis reference centers the most common findings of CSD were retinal infiltrates and angiomatous lesions. ${ }^{56}$ In another study that explored the implication of $B$. henselae, B. quintana and B. grahamii as causes of uveitis, the most common clinical entity found was posterior uveitis. ${ }^{43}$ The spectrum of intraocular manifestations of Bartonella infection is very large and this must be kept in mind.

In our series of cases there was a patient who, 1 year after the onset of the ocular disease (bilateral vitritis), had the complication of myocarditis. There is a study that reports chronic active myocarditis after $B$. henselae infection. The mechanism is believed to be that of secondary lymphocyte mediated immune response. ${ }^{71}$ This could also be the case in our patient.

The case of our patient who presented with neuroretinitis was complicated after 3 months with tubulointerstitial nephritis (possible TINU syndrome). The etiology of TINU syndrome remains unclear. TINU is thought in be an immunemediated process and there are associations with some infectious agents, several drugs and toxins. However it can be idiopathic. ${ }^{67}$ In our case, the possible TINU syndrome could be associated with $B$. henselae or the antibiotic treatment used to eradicate the microorganism. To our knowledge this is the first reported case of a possible association of Bartonella 
infection and TINU. The same patient also developed AION before the onset of interstitial nephritis. Those sequential events following neuroretinitis could suggest an immune associated mechanism triggered by Bartonella infection.

There are recent reports of anterior uveitis caused by Bartonella species ${ }^{43}$ Iridocyclitis due to Bartonella infection may be granulomatous or nongranulomatous as well and recurrent iridocyclitis has been also reported. ${ }^{72}$

Bartonella species are fastidious bacteria, difficult to grow and requiring long incubation periods in enriched media for 2 to 6 weeks. Often isolation in culture is unsuccessful. The diagnosis of Bartonella infection is commonly made using serologic testing with immunofluorescence antibody analysis (IFA) or enzyme-linked immunosorbent assay (ELISA) ${ }^{66,73}$ The sensitivities and specificities of these methods vary in different reports and different cutoff values are used. The chosen cutoff value in the serological examination (IFA) in the patients of our study reflects our effort to avoid underdiagnosis. If serology is negative, a second sample after 2 months may show a seroconversion. Cross-reactions have been reported between Bartonella species and with Coxiella burnetti and Chlamydia pneumoniae. Western blot analysis and cross-adsorption can solve this problem and increase the specificity of the test. ${ }^{34}$ Also polymerase chain reaction (PCR) analysis of tissue samples can be used for diagnosis. ${ }^{74}$ Intraocular fluid analysis using PCR can confirm the diagnosis of Bartonella intraocular inflammation as well. ${ }^{43}$

In immunocompetent patients the ocular manifestations of Bartonella infection tend to be self-limited and have a benign course. However, some patients may have more severe ocular complications, especially those with intraocular inflammation. Early antibiotic treatment seems to shorten the course of infection and hasten visual recovery ${ }^{52}$ and this was also the basis of the management of our patients with Bartonella uveitis. In immunocompromised patients, the ocular manifestations tend to be more severe and an early intensive antibiotic treatment is required. A variety of antibiotics have been reported to have good efficacy including rifampicin, doxycycline, azithromycin, ciprofloxacin, trimethoprim-sulfamethoxazole and gentamycin. The antibiotic treatment lasts 2-4 weeks for immunocompetent patients and up to 4 months for immunocompromised patients. ${ }^{16}$ In our patients, all immunocompetent, a 4-week treatment protocol was performed to eradicate the infectious agent.

Pet owners should be informed about the risks that exist from the infestation of the pets with fleas or ticks and control measures should be taken to avoid such infestation. Also homeless people, drug addicts and alcoholics should be informed of the risks that exist from the presence of human body lice and control measures should be taken as well. In addition, these individuals, because of the poor living conditions and lack of hygiene, may also be exposed to rodentborne Bartonella species. Finally, immunocompromised patients should be especially careful, because Bartonella infection can be severe or even fatal for them, and prevention is the best solution.

Intraocular involvement caused not only by $B$. henselae but also by $B$. quintana is being diagnosed with increasing frequency. The combination of POGS and intraocular inflammation in the same patient seems to be very rare and this is also observed in our own cases..$^{50}$ Although the possibility of $B$. henselae infection should be considered in patients with neuroretinitis, other forms of uveitis and retinal vasculitis may be present even in the absence of systemic symptoms of cat scratch disease, especially in cases of B. quintana infection, which is underestimated as a cause of intraocular inflammation. Serological data must be interpreted especially along with a positive history of exposure to cat-scratching or biting, and the clinical picture; a high index of suspicion should be retained, because some associations may remain underdescribed.

\section{Disclosure}

The authors report no conflicts of interest in this work.

\section{References}

1. Chomel BB, Boulouis HJ, Breitschwerdt EB, et al. Ecological fitness and strategies of adaptation of Bartonella species to their hosts and vectors. Vet Res. 2009;40(2):29.

2. Chomel BB, Abbott RC, Kasten RW, et al. Bartonella henselae prevalence in domestic cats in California: risk factors and association between bacteremia and antibody titers. J Clin Microbiol. 1995;33(9):2445-2550.

3. Chomel BB, Boulouis HJ, Petersen H, et al. Prevalence of Bartonella infection in domestic cats in Denmark. Vet Res. 2002;33(2):205-213.

4. Birtles RJ, Laycock G, Kenny MJ, Shaw SE, Day MJ. Prevalence of Bartonella species causing bacteraemia in domesticated and companion animals in the United Kingdom. Vet Rec. 2002;151(8):225-229.

5. Barnes A, Bell SC, Isherwood DR, Bennett M, Carter SD. Evidence of Bartonella henselae infection in cats and dogs in the United Kingdom. Vet Rec. 2000;147(24):673-677.

6. Fabbi M, Vicari N, Tranquillo M, et al. Prevalence of Bartonella henselae in stray and domestic cats in different Italian areas: evaluation of the potential risk of transmission of Bartonella to humans. Parassitologia. 2004;46(1-2):127-129.

7. Maruyama S, Nakamura Y, Kabeya H, Tanaka S, Sakai T, Katsube Y. Prevalence of Bartonella henselae, Bartonella clarridgeiae and the $16 \mathrm{~S}$ rRNA gene types of Bartonella henselae among pet cats in Japan. J Vet Med Sci. 2000;62(3):273-279.

8. Guptill L, Wu CC, HogenEsch H, et al. Prevalence, risk factors, and genetic diversity of Bartonella henselae infections in pet cats in four regions of the United States. J Clin Microbiol. 2004;42(2):652-659.

9. Kelly PJ, Matthewman LA, Hayter D, et al. Bartonella (Rochalimaea) henselae in southern Africa - evidence for infections in domestic cats and implications for veterinarians. J S Afr Vet Assoc. 1996;67(4): 182-187. 
10. Chomel BB, Kasten RW, Floyd-Hawkins K, et al. Experimental transmission of Bartonella henselae by the cat flea. J Clin Microbiol. 1996;34(8):1952-1956.

11. Lamas C, Curi A, Bóia M, Lemos E. Human bartonellosis: seroepidemiological and clinical features with an emphasis on data from Brazil a review. Mem Inst Oswaldo Cruz. 2008;103(3):221-235.

12. Bass JW, Vincent JM, Person DA. The expanding spectrum of Bartonella infections: II. Cat-scratch disease. Pediatr Infect Dis J. 1997;16(2): 163-179.

13. Carithers HA. Cat-scratch disease. An overview based on a study of 1,200 patients. Am J Dis Child. 1985;139(11):1124-1133.

14. Jacobs RF, Schutze GE. Bartonella henselae as a cause of prolonged fever and fever of unknown origin in children. Clin Infect Dis. 1998; 26(1):80-84.

15. Cunningham ET, Koehler JE. Ocular bartonellosis. Am J Ophthalmol. 2000;130(3):340-349.

16. Roe RH, Michael Jumper J, Fu AD, Johnson RN, Richard McDonald H, Cunningham ET. Ocular bartonella infections. Int Ophthalmol Clin. 2008;48(3):93-105.

17. Dunn MW, Berkowitz FE, Miller JJ, Snitzer JA. Hepatosplenic catscratch disease and abdominal pain. Pediatr Infect Dis J. 1997;16(3): 269-272.

18. Fournier PE, Lelievre H, Eykyn SJ, et al. Epidemiologic and clinical characteristics of Bartonella quintana and Bartonella henselae endocarditis: a study of 48 patients. Medicine (Baltimore). 2001;80(4):245-251.

19. Brouqui P, Raoult D. Endocarditis due to rare and fastidious bacteria. Clin Microbiol Rev. 2001;14(1):177-207.

20. Marra CM. Neurologic complications of Bartonella henselae infection. Curr Opin Neurol. 1995;8(3):164-169.

21. Ogura K, Hara Y, Tsukahara H, Maeda M, Tsukahara M, Mayumi M. MR signal changes in a child with cat scratch disease encephalopathy and status epilepticus. Eur Neurol. 2004;51(2):109-110.

22. Gerber JE, Johnson JE, Scott MA, Madhusudhan KT. Fatal meningitis and encephalitis due to Bartonella henselae bacteria. J Forensic Sci. 2002;47(3):640-644.

23. van Tooren RM, van Leusen R, Bosch FH. Culture negative endocarditis combined with glomerulonephritis caused by Bartonella species in two immunocompetent adults. Neth J Med. 2001;59(5):218-224.

24. Vermeulen MJ, Rutten GJ, Verhagen I, Peeters MF, van Dijken PJ. Transient paresis associated with cat-scratch disease: case report and literature review of vertebral osteomyelitis caused by Bartonella henselae. Pediatr Infect Dis J. 2006;25(12):1177-1181

25. Tsukahara M, Tsuneoka H, Tateishi H, Fujita K, Uchida M. Bartonella infection associated with systemic juvenile rheumatoid arthritis. Clin Infect Dis. 2001;32(1):E22-E23.

26. Wong TZ, Kruskal J, Kane RA, Trey G. Cat-scratch disease simulating lymphoma. J Comput Assist Tomogr. 1996;20(1):165-166.

27. Markaki S, Sotiropoulou M, Papaspirou P, Lazaris D. Cat-scratch disease presenting as a solitary tumour in the breast: report of three cases. Eur J Obstet Gynecol Reprod Biol. 2003;106(2): $175-178$.

28. Millot F, Tailboux L, Paccalin M, et al. Cat-scratch disease simulating a malignant process of the chest wall. Eur J Pediatr. 1999;158(5): 403-405.

29. Marr BP, Shields CL, Shields JA, Eagle RC Jr. Conjunctival catscratch disease simulating rhabdomyosarcoma. $J$ Pediatr Ophthalmol Strabismus. 2003;40(5):302-303.

30. Kempf VA, Petzold H, Autenrieth IB. Cat scratch disease due to Bartonella henselae infection mimicking parotid malignancy. Eur $J$ Clin Microbiol Infect Dis. 2001;20(10):732-733.

31. Chomel BB. Cat-scratch disease and bacillary angiomatosis. Rev Sci Tech. 1996;15(3):1061-1073.

32. Koehler JE. Bartonella-associated infections in HIV-infected patients. AIDS Clin Care. 1995;7(12):97-102.

33. Nadal D, Zbinden R. Illnesses caused by Bartonella. Cat-scratch disease, bacillary angiomatosis, bacillary peliosis hepatis, endocarditis. Internist (Berl). 1996;37(9):890-894.
34. Foucault C, Brouqui P, Raoult D. Bartonella quintana characteristics and clinical management. Emerg Infect Dis. 2006;12(2):217-223.

35. Bonilla DL, Kabeya H, Henn J, Kramer VL, Kosoy MY. Bartonella quintana in body lice and head lice from homeless persons, San Francisco, California, USA. Emerg Infect Dis. 2009;15(6):912-915.

36. Brouqui P, Houpikian P, Dupont HT, et al. Survey of the seroprevalence of Bartonella quintana in homeless people. Clin Infect Dis. 1996;23(4):756-759.

37. Seki N, Sasaki T, Sawabe K, et al. Epidemiological studies on Bartonella quintana infections among homeless people in Tokyo, Japan. Jpn J Infect Dis. 2006;59(1):31-35.

38. Comer JA, Flynn C, Regnery RL, Vlahov D, Childs JE. Antibodies to Bartonella species in inner-city intravenous drug users in Baltimore, Md. Arch Intern Med. 1996;156(21):2491-2495.

39. Breitschwerdt EB, Maggi RG, Sigmon B, Nicholson WL. Isolation of Bartonella quintana from a woman and a cat following putative bite transmission. J Clin Microbiol. 2007;45(1):270-272.

40. La VD, Tran-Hung L, Aboudharam G, Raoult D, Drancourt M. Bartonella quintana in domestic cat. Emerg Infect Dis. 2005;11(8):1287-1289.

41. O'Rourke LG, Pitulle C, Hegarty BC, et al. Bartonella quintana in cynomolgus monkey (Macaca fascicularis). Emerg Infect Dis. 2005;11(12): 1931-1934.

42. Karem KL, Paddock CD, Regnery RL. Bartonella henselae, B. quintana, and B. bacilliformis: historical pathogens of emerging significance. Microbes Infect. 2000;2(10):1193-1205.

43. Terrada C, Bodaghi B, Conrath J, Raoult D, Drancourt M. Uveitis: an emerging clinical form of Bartonella infection. Clin Microbiol Infect. 2009;15(Suppl 2):132-133.

44. Parinaud H. Conjunctivite infectieuse transmise par les animaux. Ann d'Oculistique 1889;101:252-253.

45. Borboli S, Afshari NA, Watkins L, Foster CS. Presumed oculoglandular syndrome from Bartonella quintana. Ocul Immunol Inflamm. 2007; 15(1):41-43.

46. Ormerod LD, Dailey JP. Ocular manifestations of cat-scratch disease. Curr Opin Ophthalmol. 1999;10(3):209-216.

47. Suhler EB, Lauer AK, Rosenbaum JT. Prevalence of serologic evidence of cat scratch disease in patients with neuroretinitis. Ophthalmology. 2000;107(5):871-876.

48. Eggenberger E. Cat scratch disease: posterior segment manifestations. Ophthalmology. 2000;107(5):817-818.

49. Wade NK, Po S, Wong IG, Cunningham ET Jr. Bilateral Bartonellaassociated neuroretinitis. Retina. 1999;19(4):355-356.

50. Wong MT, Dolan MJ, Lattuada CP Jr, et al. Neuroretinitis, aseptic meningitis, and lymphadenitis associated with Bartonella (Rochalimaea) henselae infection in immunocompetent patients and patients infected with human immunodeficiency virus type 1. Clin Infect Dis. 1995;21(2):352-360.

51. Wade NK, Levi L, Jones MR, Bhisitkul R, Fine L, Cunningham ET Jr. Optic disk edema associated with peripapillary serous retinal detachment: an early sign of systemic Bartonella henselae infection. $\mathrm{Am} \mathrm{J}$ Ophthalmol. 2000;130(3):327-334.

52. Reed JB, Scales DK, Wong MT, Lattuada CP Jr, Dolan MJ, Schwab IR. Bartonella henselae neuroretinitis in cat scratch disease. Diagnosis, management, and sequelae. Ophthalmology. 1998;105(3):459-466.

53. George JG, Bradley JC, Kimbrough RC 3rd, Shami MJ. Bartonella quintana associated neuroretinitis. Scand J Infect Dis. 2006;38(2):127-128.

54. Kerkhoff FT, Bergmans AM, van Der Zee A, Rothova A. Demonstration of Bartonella grahamii DNA in ocular fluids of a patient with neuroretinitis. J Clin Microbiol. 1999;37(12):4034-4038.

55. O'Halloran HS, Draud K, Minix M, Rivard AK, Pearson PA. Leber's Neuroretinitis in a patient with serologic evidence of Bartonella elizabethae. Retina. 1998;18(3):276-278.

56. Curi AL, Machado D, Heringer G, et al. Cat-scratch disease: ocular manifestations and visual outcome. Int Ophthalmol. 2010;30(5)553-558.

57. Ormerod LD, Skolnick KA, Menosky MM, Pavan PR, Pon DM. Retinal and choroidal manifestations of cat-scratch disease. Ophthalmology. 1998;105(6):1024-1031. 
58. Khurana RN, Albini T, Green RL, Rao NA, Lim JI. Bartonella henselae infection presenting as a unilateral panuveitis simulating Vogt-Koyanagi-Harada syndrome. Am J Ophthalmol. 2004;138(6): 1063-1065.

59. Donnio A, Jean-Charles A, Merle H. Macular hole following Bartonella henselae neuroretinitis. Eur J Ophthalmol. 2008;18(3):456-458.

60. Gray AV, Michels KS, Lauer AK, Samples JR. Bartonella henselae infection associated with neuroretinitis, central retinal artery and vein occlusion, neovascular glaucoma, and severe vision loss. Am J Ophthalmol. 2004;137(1):187-189.

61. Kawasaki A, Wilson DL. Mass lesions of the posterior segment associated with Bartonella henselae. Br J Ophthalmol. 2003;87(2):248-249.

62. Gray AV, Reed JB, Wendel RT, Morse LS. Bartonella henselae infection associated with peripapillary angioma, branch retinal artery occlusion, and severe vision loss. Am J Ophthalmol. 1999;127(2):223-224.

63. Serratrice J, Rolain JM, Granel B, et al. Bilateral retinal artery branch occlusions revealing Bartonella grahamii infection. Rev Med Interne. 2003;24(9):629-630. French.

64. Curi AL, Machado DO, Heringer G, Campos WR, Orefice F. Ocular manifestation of cat-scratch disease in HIV-positive patients. Am J Ophthalmol. 2006;141(2):400-401.

65. Soheilian M, Markomichelakis N, Foster CS. Intermediate uveitis and retinal vasculitis as manifestations of cat scratch disease. $\mathrm{Am}$ J Ophthalmol. 1996;122(4):582-584.

66. Amerein MP, De Briel D, Jaulhac B, Meyer P, Monteil H, Piemont Y. Diagnostic value of the indirect immunofluorescence assay in cat scratch disease with Bartonella henselae and Afipia felis antigens. Clin Diagn Lab Immunol. 1996;3(2):200-204.
67. Mandeville J, Levinson R, Holland G. The tubulointerstitial nephritis and uveitis syndrome. Surv Ophthalmol. 2001;46(3):195-208.

68. Pipili C, Katsogridakis K, Cholongitas E. Myocarditis due to Bartonella henselae. South Med J. 2008;101(11):1186.

69. Jabs DA, Nussenblatt RB, Rosenbaum JT; Standardization of Uveitis Nomenclature (SUN) Working Group. Standardization of uveitis nomenclature for reporting clinical data. Results of the First International Workshop. Am J Ophthalmol. 2005;140(3):509-516.

70. Solley WA, Martin DF, Newman NJ, et al. Cat scratch disease: posterior segment manifestations. Ophthalmology. 1999;106(8): $1546-1553$.

71. Meininger GR, Nadasdy T, Hruban RH, Bollinger RC, Baughman KL, Hare JM. Chronic active myocarditis following acute Bartonella henselae infection (cat scratch disease). Am J Surg Pathol. 2001;25(9): 1211-1214

72. Martínez-Osorio H, Calonge M, Torres J, González F. Cat-scratch disease (ocular bartonellosis) presenting as bilateral recurrent iridocyclitis. Clin Infect Dis. 2005;40(5):e43-e45.

73. Regnery RL, Olson JG, Perkins BA, Bibb W. Serological response to "Rochalimaea henselae" antigen in suspected cat-scratch disease. Lancet. 1992;339(8807):1443-1445.

74. Hansmann Y, DeMartino S, Piémont Y, Meyer N, Mariet P, Heller R, et al. Diagnosis of cat scratch disease with detection of Bartonella henselae by PCR: a study of patients with lymph node enlargement J Clin Microbiol. 2005;43(8):3800-3806.
Clinical Ophthalmology

\section{Publish your work in this journal}

Clinical Ophthalmology is an international, peer-reviewed journal covering all subspecialties within ophthalmology. Key topics include: Optometry; Visual science; Pharmacology and drug therapy in eye diseases; Basic Sciences; Primary and Secondary eye care; Patient Safety and Quality of Care Improvements. This journal is indexed on

Submit your manuscript here: http://www.dovepress.com/clinical-ophthalmology-journal

\section{Dovepress}

PubMed Central and CAS, and is the official journal of The Society of Clinical Ophthalmology (SCO). The manuscript management system is completely online and includes a very quick and fair peer-review system, which is all easy to use. Visit http://www.dovepress.com/ testimonials.php to read real quotes from published authors. 